\title{
Neck circumference and success in the weight-reducing treatment of patients with obesity: a real-life study
}

\section{Martha Kaufer-Horwitz, * María Gisela Carreto-Adán and Fernando Pérez-Hernández}

Instituto Nacional de Ciencias Médicas y Nutrición Salvador Zubirán, Obesity and Eating Disorders Clinic, Department of Endocrinology and Metabolism, Mexico City, Mexico

\begin{abstract}
Introduction: Evaluation of the patient with obesity is a challenge due to the technical difficulties to carry out measurements. Objective: To assess the association between neck circumference (NC) and waist circumference (WC) with cardio-metabolic risk markers, as well as treatment success in patients with morbid obesity. Method: Four-hundred and seventy patients of 39.3 \pm 11.4 years of age and with a body mass index (BMI) of $44.1 \pm 8.4$ were studied; $73.5 \%$ were females. Baseline and final BMI, WC, NC, hip circumference and cardio-metabolic markers were assessed. Success was defined as weight loss $\geq 5 \%$. Results: Significant correlations were found between WC and NC, and between these and cardio-metabolic risk markers, as well as between changes in WC and NC and treatment success. NC predicted success in logistic regression models. Conclusions: The association of WC and NC with cardio-metabolic risk indicators and the association of NC with treatment success in patients with morbid obesity was documented. Given the simplicity for obtaining it, NC might replace WC in the assessment and follow-up of patients with class III obesity.
\end{abstract}

KEY WORDS: Neck circumference. Waist circumference. Body mass index. Obesity. Adults.

\section{Perímetro de cuello y éxito del tratamiento de pacientes con obesidad: estudio de vida real}

\section{Resumen}

Introducción: La evaluación del paciente con obesidad es un reto debido a las dificultades técnicas para efectuar las mediciones. Objetivo: Evaluar la asociación entre el perímetro de cuello (PCu) y el de cintura (PC) con marcadores de riesgo cardiometabólico y el éxito del tratamiento de pacientes con obesidad mórbida. Método: Se estudiaron 470 pacientes de $39.3 \pm 11.4$ años e índice de masa corporal de $44.1 \pm 8.4 ; 73.5 \%$ era del sexo femenino. Se evaluó índice de masa corporal, $P C, P C u$, perímetro de cadera y marcadores cardiometabólicos basales y finales. Se definió como éxito a una pérdida ponderal $\geq 5 \%$. Resultados: Se encontraron correlaciones significativas entre PC y PCu y entre estos y marcadores de riesgo cardiometabólico, así como entre los cambios en PC y PCu y el éxito en el tratamiento. El PCu predijo el éxito en modelos de regresión logística. Conclusiones: Se documentó la asociación entre PC y PCu con indicadores de riesgo cardiometabólico y la asociación del PCu con éxito en el tratamiento en pacientes con obesidad mórbida. Dada la sencillez de su obtención, el PCu podría sustituir al PC en la evaluación y seguimiento de pacientes con obesidad clase III.

PALABRAS CLAVE: Perímetro de cuello. Perímetro de cintura. Índice de masa corporal. Obesidad. Adultos. 


\section{Introduction}

Obesity is a public health problem at globally. ${ }^{1}$ In Mexico, the prevalence of overweight and obesity has shown an upward trend since 1988, and in 2016 it reached a combined prevalence (overweight + obesity) of $72.5 \%$ in adults. ${ }^{2}$

Obesity is a disease that is characterized by an abnormal increase in adiposity. Even when the body mass index (BMI) measures mass rather than adiposity, it has been used to define and assess obesity for epidemiological and clinical purposes. The measurement of fat, particularly visceral fat, requires methods that are not readily accessible in clinical practice, ${ }^{3}$ although there are alternatives such as measuring the waist (WC), hip and, more recently, neck circumference (NC). ${ }^{4} \mathrm{BMI}$ combined with central adiposity indicators such as WC has been proposed, since it is predictive of cardiometabolic risk. ${ }^{5}$ However, although WC is a low-cost practical measure and its association with metabolic risk markers is high, there are technical problems in people with obesity and its convenience in individuals with $\mathrm{BMI} \geq 35$ has been questioned due to its low accuracy and reproducibility, to the difficulty to identify bone referents $s^{6,7}$ and to the fact that the measurement can vary due to postprandial distension, breathing and clothing. ${ }^{8,9}$

Like WC, NC is an indicator of upper body adiposity and central obesity ${ }_{10}^{10}$ although its use is less widespread and there is a lack of unified risk criteria. It is a low-cost measurement that is quick and easy to perform by trained personnel, it is more reproducible than WC and has been proposed as an alternative to assess patients with overweight or obesity because it has less technical difficulties, it is more stable and it is not subject to postprandial distention. ${ }^{9}$

The relationship of NC with the diagnosis, evaluation and follow-up of patients with overweight or obesity, ${ }^{9}$ obstructive sleep apnea-hypopnea syndrome, ${ }^{11-13}$ insulin resistance,$^{14}$ hypertension ${ }^{15}$ or cardiovascular risk has been explored: ${ }^{16}$ in addition, it is associated with metabolic syndrome. ${ }^{6,17}$ To the best of our knowledge, there are only few studies ${ }^{18,19}$ that have explored the relationship between WC and NC in patients with morbid obesity, as well as with success in obesity treatment programs.

At the Obesity and Eating Disorders Clinic of the National Institute of Medical Sciences and Nutrition Salvador Zubirán, the Program for the Care of the Patient with Obesity has been implemented. It offers comprehensive treatment, with medical, nutritional and psychological care, through a 20-week psychoeducational program with monthly visits. It includes a standardized nutritional plan, medical treatment of comorbidities and psychological support to promote treatment adherence. More than $70 \%$ of patients participating in the program has morbid obesity (BMI $\geq 40$ or $\geq 35$ in the presence of comorbidities).

In order to explore the usefulness of NC in patients with obesity, particularly morbid obesity, the purpose of the present study was to assess the association between WC and NC in patients participating in this program and their association with cardiometabolic risk markers, as well as with treatment success.

\section{Method}

Real-life study, ${ }^{20}$ consisting of a retrospective analysis of a cohort of 470 patients who were newly admitted to the Program for the Care of the Patient with Obesity between April 2004 and July 2010, concluded the program and had complete data on baseline and final anthropometric variables. Patients aged between 18 and 59 years, with $\mathrm{BMI} \geq 30$ and at least complete elementary education were included.

Weight, height, WC, hip circumference and NC were assessed. The measurements were made by standardized nutritionists using methods accepted by international consensus. ${ }^{21}$ Weight was obtained with a TANITA bioelectrical impedance scale with $250-\mathrm{kg}$ weight capacity, with the patient wearing light clothes and no shoes; height was measured with a wall stadiometer with flexometer. Circumferences were measured with a fiberglass measuring tape (SECA 201). WC was measured at the midpoint between the lower border of the rib cage and the iliac ridges at the level of the axillary midline at the height of the umbilical scar, and hip circumference, at the widest point of the gluteal perimeter. NC was measured just below the laryngeal prominence, with the head on the Frankfort plane. ${ }^{15,21} \mathrm{BMI}\left(\mathrm{kg} / \mathrm{m}^{2}\right)$ and waist/hip index were calculated. Blood pressure was measured using a wall aneroid sphygmomanometer with an appropriate size cuff. ${ }^{22}$ Fasting glucose and lipid profile (total cholesterol, LDL cholesterol, HDL cholesterol and triglycerides) were determined at the Central Laboratory of the National Institute of Medical Sciences and Nutrition Salvador Zubirán. Metabolic syndrome was defined as the presence of three or more components of Alberti's harmonized criteria. ${ }^{23}$ Treatment was considered successful with a weight reduction $\geq 5 \%{ }^{6}$ 
Table 1. Baseline and final clinical and metabolic characteristics, by gender

\begin{tabular}{|c|c|c|c|c|c|c|c|c|c|c|}
\hline & \multicolumn{5}{|c|}{ Males $(n=123)$} & \multicolumn{5}{|c|}{ Females $(n=347)$} \\
\hline & \multicolumn{2}{|c|}{ Baseline } & \multicolumn{2}{|c|}{ Final } & $\mathbf{p}^{*}$ & \multicolumn{2}{|c|}{ Baseline } & \multicolumn{2}{|c|}{ Final } & $p^{*}$ \\
\hline & \multicolumn{2}{|c|}{ Mean \pm SD } & \multicolumn{2}{|c|}{ Mean \pm SD } & & \multicolumn{2}{|c|}{ Mean \pm SD } & \multicolumn{2}{|c|}{ Mean \pm SD } & \\
\hline Age (years) & \multicolumn{2}{|c|}{$38.6 \pm 11.9$} & & & & \multicolumn{2}{|c|}{$39.2 \pm 11.3$} & & & \\
\hline Height (m) & \multicolumn{2}{|c|}{$1.71 \pm 0.07$} & & & & \multicolumn{2}{|c|}{$1.58 \pm 0.07$} & & & \\
\hline Weight (kg) & \multicolumn{2}{|c|}{$133.8 \pm 30.0$} & \multicolumn{2}{|c|}{$126.2 \pm 28.8$} & 0.000 & \multicolumn{2}{|c|}{$109.2 \pm 21.9$} & \multicolumn{2}{|c|}{$104.1 \pm 21.3$} & 0.000 \\
\hline BMI & \multicolumn{2}{|c|}{$45.4 \pm 8.9$} & \multicolumn{2}{|c|}{$42.8 \pm 9.0$} & 0.000 & \multicolumn{2}{|c|}{$43.7 \pm 8.2$} & \multicolumn{2}{|c|}{$41.7 \pm 8.0$} & 0.000 \\
\hline Waist circumference (cm) & \multicolumn{2}{|c|}{$136.5 \pm 18.1$} & \multicolumn{2}{|c|}{$129.9 \pm 18.5$} & 0.000 & \multicolumn{2}{|c|}{$118.4 \pm 16.9$} & \multicolumn{2}{|c|}{$113.9 \pm 16.2$} & 0.000 \\
\hline Hip circumference (cm) & \multicolumn{2}{|c|}{$134.5 \pm 18.3$} & \multicolumn{2}{|c|}{$129.9 \pm 18.2$} & 0.000 & \multicolumn{2}{|c|}{$135.7 \pm 15.8$} & \multicolumn{2}{|c|}{$132.0 \pm 16.2$} & 0.000 \\
\hline Waist/hip index & \multicolumn{2}{|c|}{$1.02 \pm 0.07$} & & .07 & 0.004 & 0.87 & 0.08 & 0.86 & 0.07 & 0.000 \\
\hline Neck circumference (cm) & 46. & 3.4 & & 4.1 & 0.000 & 39.6 & 3.5 & 38. & 3.7 & 0.000 \\
\hline Systolic blood pressure (mm Hg) & 133.5 & 14.9 & 126 & 13.5 & 0.000 & 129. & 15.2 & 125 & 14.1 & 0.000 \\
\hline Diastolic blood pressure (mm Hg) & 87.1 & 10.8 & 83. & & 0.001 & 84.0 & 11.0 & 81. & 9.3 & 0.000 \\
\hline Glucose (mg/dL) & 101.2 & 20.1 & 99. & 36.5 & 0.497 & 103.3 & 26.1 & 97.1 & 21.6 & 0.000 \\
\hline Total cholesterol (mg/dL) & 184. & 34.2 & 173 & 38.4 & 0.036 & 190.3 & 38.5 & 184 & 37.3 & 0.006 \\
\hline Triglycerides (mg/dL) & 182.2 & 78.0 & 159 & 70.2 & 0.022 & 170. & 89.4 & 158 & 76.3 & 0.001 \\
\hline LDL-cholesterol (mg/dL) & 112 & 28.7 & 95. & 37.4 & 0.035 & 118.5 & 32.2 & 108 & 40.8 & 0.001 \\
\hline HDL-cholesterol (mg/dL) & 33.6 & 6.7 & & 8.2 & 0.301 & 38.8 & 9.0 & 39. & 9.1 & 0.752 \\
\hline Metabolic syndrome components\# & 3.59 & 1.04 & 3.0 & 1.05 & 0.001 & 3.43 & 1.03 & 3.05 & 0.67 & 0.000 \\
\hline & n & $\%$ & n & $\%$ & $p^{\S}$ & n & $\%$ & $\mathrm{n}$ & $\%$ & $p^{\S}$ \\
\hline Altered glucose & 50 & 40.7 & 26 & 21.1 & 0.000 & 148 & 42.7 & 65 & 18.7 & 0.000 \\
\hline Altered triglycerides & 68 & 55.5 & 44 & 35.8 & 0.001 & 168 & 48.4 & 100 & 28.8 & 0.000 \\
\hline Altered HDL-cholesterol & 97 & 78.9 & 62 & 50.4 & 0.000 & 296 & 85.3 & 203 & 58.5 & 0.000 \\
\hline Altered blood pressure & 95 & 77.2 & 64 & 52.0 & 0.000 & 211 & 60.8 & 160 & 46.1 & 0.041 \\
\hline Metabolic syndrome ${ }^{\#}$ & 65 & 81.3 & 58 & 72.5 & 0.005 & 171 & 81.0 & 145 & 68.7 & 0.000 \\
\hline
\end{tabular}

${ }^{*}$ Paired t-test. ${ }^{8}$ Chi-square test. "Males $n=80$; females $n=211$ with baseline and final assessment for all components of the metabolic syndrome.

The study was approved by the Institute's own Ethics in Reasearch and Research Committees. All participants granted written informed consent upon entering the Program for the Care of the Patient with Obesity.

Central tendency and dispersion measures were determined (mean, standard deviation) for continuous variables, and frequencies and percentages for categorical variables. A simple correlation analysis (Pearson's $r$ ) was carried out between anthropometric and cardiometabolic risk variables and Spearman correlation analysis between success and changes in WC and NC. To assess mean differences (baseline and final), a paired t-test was used, assuming equality or non-equality of variances according to Levene's test
(F) or chi-square test results for categorical variables. Logistic regression models were generated for treatment success, and odds ratios and their $95 \%$ confidence intervals were estimated. All analyses were made divided by gender and statistical significance was considered with a $p$-value $<0.05$. The SPSS program version 22.0 for Windows was used.

\section{Results}

Four-hundred and seventy patients with obesity were studied (BMI ranging from 30.2 to 77.7 ); $73.5 \%$ were females. Age was $39.3 \pm 11.4$ years and baseline weight and BMl were $115.7 \pm 26.6 \mathrm{~kg}$ and $44.1 \pm 8.4$, 
respectively; $63.6 \%$ of patients had a BMI $\geq 40$ (with no differences between genders), which indicated class III obesity according to the World Health Organization criteria. ${ }^{24}$ In both genders, WC indicated abdominal obesity ${ }^{23}$ and NC showed values higher than those reported in different studies. ${ }^{8}$ Metabolic parameters had values consistent with the metabolic syndrome components and only total cholesterol showed mean values within normal. At baseline, all patients had altered WC and $78.9 \%$ of males and $85.3 \%$ of females had hypoalphalipoproteinemia (Table 1).

Significant differences were found in WC, hip circumference and NC $(p<0.001)$ when patients were divided by $\mathrm{BMI}<35$ and $\geq 35$ groups. Females with $\mathrm{BMI} \geq 35$ had higher values for systolic blood pressure, diastolic blood pressure, glucose, and lower for LDL-cholesterol and HDL-cholesterol $(p<0.01$ for systolic blood pressure and diastolic blood pressure and $\mathrm{p}<0.05$ in all other cases) than those with $\mathrm{BMI}<35$. No differences in cardiometabolic risk parameters were found in men by BMI group.

A significant improvement was documented in anthropometric, clinical and metabolic indicators at the end of the program in both genders, except for glucose in females and HDL-cholesterol in males and females (Table 1).

When the variables were contrasted by BMI group, significantly higher values in weight, BMI, WC, hip circumference, NC, systolic blood pressure, diastolic blood pressure, glucose, LDL-cholesterol and $\mathrm{HDL}$-cholesterol were found in females with $\mathrm{BMI} \geq 35$, while only differences in anthropometric variables were found in males.

There was a significant decrease in the prevalence of altered markers, except for WC. The evolution of metabolic syndrome and its components was studied in 80 males and 211 females with complete data for these markers. At baseline, $81.3 \%$ of males and $81 \%$ of females had metabolic syndrome. At the end of the program, a reduction in the number of metabolic syndrome components was documented $(p=0.001$ in males and $p=0.000$ in females) and their frequency was reduced $(p=0.005$ in males and $p=0.000$ in females) (Table 1). The frequency of metabolic syndrome in females with $\mathrm{BMI} \geq 35$ was higher than in those with $\mathrm{BMI}<35(82.4 \%$ versus $60.0 \%, \mathrm{p}=0.000)$; this did not occur in males $(84.1 \%$ versus $63.6 \%, p=0.202)$.

A positive and significant correlation was found between WC and NC in males and females (0.353 and 0.558 , respectively; $p<0.01$ ). In males, reverse correlations of BMI, WC y NC with cholesterol and
Table 2. Pearson's correlation between anthropometric variables and cardiometabolic indicators at baseline, by gender

\begin{tabular}{|c|c|c|c|c|}
\hline & Risk variables & BMI & Waist & Neck \\
\hline \multirow[t]{7}{*}{ Males } & Glucose & -0.099 & -0.073 & -0.084 \\
\hline & Triglycerides & -0.075 & -0.087 & -0.049 \\
\hline & Cholesterol & $-0.248^{\star \star}$ & $-0.239^{\star \star}$ & $-0.216^{\star}$ \\
\hline & HDL-cholesterol & -0.167 & -0.148 & -0.126 \\
\hline & LDL-cholesterol & $-0.233^{*}$ & $-0.215^{\star}$ & $-0.228^{\star}$ \\
\hline & Systolic blood pressure & $0.232^{\star *}$ & $0.235^{\star \star}$ & 0.144 \\
\hline & Diastolic blood pressure & $0.213^{*}$ & $0.188^{*}$ & 0.166 \\
\hline \multirow[t]{7}{*}{ Females } & Glucose & $0.142^{* *}$ & $0.149^{\star \star}$ & 0.105 \\
\hline & Triglycerides & 0.069 & 0.005 & $0.138^{*}$ \\
\hline & Cholesterol & -0.026 & 0.036 & 0.088 \\
\hline & HDL-cholesterol & $-0.109^{*}$ & $-0.130^{*}$ & $-0.126^{*}$ \\
\hline & LDL-cholesterol & -0.030 & 0.018 & 0.056 \\
\hline & Systolic blood pressure & $0.214^{* *}$ & $0.140^{*}$ & $0.162^{\star *}$ \\
\hline & Diastolic blood pressure & $0.199^{* *}$ & $0.153^{\star \star}$ & $0.121^{*}$ \\
\hline
\end{tabular}

Baseline values were used

${ }^{\star} p<0.05 ;{ }^{* *} p<0.01$

LDL-cholesterol, and positive correlations of BMI and WC with systolic blood pressure and diastolic blood pressure were documented. In females, significant correlations of $\mathrm{BMI}, \mathrm{WC}$ and NC with systolic and diastolic blood pressure and HDL-cholesterol were found, as well as of BMI and WC with glucose and of NC with triglycerides. The direction of the correlations was as expected except for cholesterol and LDL-cholesterol in males (Table 2).

Median weight loss in males was $7.6 \mathrm{~kg} \mathrm{(-28.8} \mathrm{to} \mathrm{+}$ $9.2 \mathrm{~kg})$, and $4.4 \mathrm{~kg}(-28.8$ to $+7.2 \mathrm{~kg})$ in females; $56.1 \%$ of males and $42.1 \%$ of females had weight loss $\geq 5 \%$, with significant differences between genders $(p=0.007)$.

Significant correlations were found between WC and NC changes and weight loss percentage or treatment success, except for NC changes and weight loss percentage in females with $\mathrm{BMI}<35$. Correlations were higher in males. WC showed higher correlations than NC. High correlations of WC with weight loss percentage and success stand out in males and females with $\mathrm{BMI}<35$ (Table 3).

$\mathrm{NC}$ was included in all regression models, except for model 4, while WC was not included in any. Model 3 had higher $r^{2}$ and explained $21.7 \%$ of variance of the dependent variable (success) with three variables: age, neck circumference and fasting glucose (Table 4). 
Table 3. Correlation between changes in waist and neck circumference and outcome variables (\% of weight loss or success)

\begin{tabular}{|c|c|c|c|c|}
\hline & Outcome variable & BMI & Waist changes & Neck changes \\
\hline \multirow[t]{4}{*}{ Males } & \multirow[t]{3}{*}{ Weight loss \%\# } & All & $0.472^{* *}$ & $0.329^{\star \star}$ \\
\hline & & $\mathrm{BMI}<35$ & $0.823^{* *}$ & $0.718^{*}$ \\
\hline & & $\mathrm{BMI} \geq 35$ & $0.456^{\star *}$ & $0.316^{\star \star}$ \\
\hline & Success\& & All & $0.461^{* *}$ & $0.384^{* \star}$ \\
\hline \multirow[t]{4}{*}{ Women } & \multirow[t]{3}{*}{ Weight loss \%" } & All & $0.475^{\star *}$ & $0.201^{* *}$ \\
\hline & & $\mathrm{BMI}<35$ & $0.630^{* *}$ & 0.258 \\
\hline & & $\mathrm{BMI} \geq 35$ & $0.454^{\star *}$ & $0.191^{\star *}$ \\
\hline & Success\& & All & $0.361^{* *}$ & $0.251^{* \star}$ \\
\hline
\end{tabular}

\#Pearson's correlation. ${ }^{8}$ Spearman's correlation (neck and waist as dichotomous variables and percentile 66 as cutoff point by gender). ${ }^{*} p<0.05$. ${ }^{* *} p<0.001$.

Table 4. Forward stepwise logistic regression models for treatment success ( $\geq 5 \%$ of weight loss)

\begin{tabular}{|c|c|c|c|c|c|c|}
\hline \multirow[t]{2}{*}{ Model } & \multirow[t]{2}{*}{ Variables in the model } & \multirow[t]{2}{*}{ OR } & \multicolumn{2}{|c|}{$95 \%$ confidence interval } & \multirow[t]{2}{*}{ p } & \multirow[t]{2}{*}{$r^{2}$} \\
\hline & & & Lower & Upper & & \\
\hline \multirow[t]{2}{*}{1} & Neck & 1.076 & 1.030 & 1.124 & 0.004 & \\
\hline & Hip & 0.988 & 0.976 & 0.999 & 0.039 & 0.035 \\
\hline \multirow[t]{2}{*}{2} & Age & 1.022 & 1.003 & 1.040 & 0.020 & \\
\hline & Neck & 1.053 & 1.008 & 1.100 & 0.021 & 0.036 \\
\hline \multirow[t]{3}{*}{3} & Age & 1.051 & 1.013 & 1.092 & 0.009 & \\
\hline & Neck & 1.150 & 1.012 & 1.305 & 0.032 & \\
\hline & Glucose & 1.032 & 1.003 & 1.062 & 0.002 & 0.217 \\
\hline 4 & Diastolic blood pressure & 1.022 & 1.000 & 1.044 & 0.049 & 0.049 \\
\hline
\end{tabular}

Independent variables (all corresponding to baseline values):

Model 1: gender, age, body mass index, waist, hip, neck.

Model 2: model 1 and systolic blood pressure, diastolic blood pressure, glucose, triglycerides, total cholesterol, HDL-cholesterol, LDL-cholesterol

Model 3: model 2 (except for gender) in males.

Model 4: model 2 (except for gender) in females.

\section{Discussion}

The present study assessed the association of NC and WC with cardiometabolic risk markers and treatment success in patients undergoing an obesity treatment program in a tertiary care institution in a real-life setting. There was a predominance of class III obesity, and $45.7 \%$ of the patients succeeded by reaching a weight loss $\geq 5 \%$ with an improvement in cardio-metabolic risk indicators.

Due to the nature of the patients, the NC values were higher than the reported cutoff points. ${ }^{8}$ As in other studies, a significant correlation of WC with NC was identified in males and females, although with lower values (0.353 in males and 0.558 in females); however, the frequency of class III obesity was high and the BMI values higher than those previously reported, ${ }^{15,19}$ even in the meta-analysis by Kroll et al. ${ }^{8}$

Although the correlations of WC and NC with metabolic risk markers were not high, they were significant (Table 2); however, throughout the treatment, higher correlations of WC or NC changes with outcome variables such as weight loss percentage or treatment success were documented (Table 3 ), as well as a relative superiority of WC over NC in all cases, even against expectations in patients with $\mathrm{BMI} \geq 35$, where the WC measurement is often inaccurate and poorly reproducible. ${ }^{6,7} \mathrm{NC}$ predicted treatment success in logistic regression models, albeit with low odds ratios and explanatory power. 
The results suggest that NC is an indicator of central adiposity given that, as in other studies, ${ }^{5,15}$ it was associated with cardiovascular risk indicators (total cholesterol, LDL-cholesterol, triglycerides and blood pressure). NC has been documented to show a high correlation $(r=0.4196, p<0.001)$, even higher than $\mathrm{BMI}$, with 10-year risk of coronary heart disease. ${ }^{9}$

Our study has limitations: being a real-life study, some data were missing, particularly in biochemical variables, possibly due to scarcity of patient resources or minimal request for tests when resources are limited. However, controlled clinical trials do not reflect usual clinical practice, and generating real life evidence for this purpose is required. ${ }^{25}$ The prevalence of metabolic syndrome might be underestimated in this study, since there was a lack of information on patients with risk variables at normal values who received or started treatment during the program. The change in WC should be taken with caution in patients with $\mathrm{BMI} \geq 35$. Nevertheless, the study contributes information to existing literature by including a large proportion of patients with class III obesity, with unusually high BMI values (40 to 77 ), rarely described, which allowed studying NC in a wide range of BMI values and its possible usefulness beyond classical anthropometric measurements. ${ }^{26}$

Although in the present study NC was not superior to WC, successful correlations with the treatment and metabolic changes were similar and suggest that NC could be a time-saving tool in the office that is less invasive than WC.

In conclusion, the present study documented the association of WC and NC with cardiometabolic risk indicators and the association of NC with treatment success in patients with morbid obesity and could be an alternative to WC in the evaluation, diagnosis and follow-up of these patients. Being an indicator of central adiposity and being associated with common comorbidities, NC might complement BMI.

\section{Acknowledgements}

To the patients of the Obesity and Eating Disorders Clinic of the National Institute of Medical Sciences and Nutrition Salvador Zubirán, as well as to the multidisciplinary team that offers them quality care.

\section{References}

1. Independent Expert Group of the Global Nutrition Report. 2018 Globa Nutrition Report: shining a light to spur action on nutrition. Reino Unido: Development Initiatives; 2018
2. Shamah-Levy T, Ruiz-Matus C, Rivera-Dommarco J, Kuri-Morales $P$, Cuevas-Nasu L, Jiménez-Corona ME, et al. Encuesta Nacional de Salud y Nutrición de Medio Camino 2016. Resultados Nacionales. Cuernavaca, México: Instituto Nacional de Salud Pública; 2017.

3. Lee SY, Gallagher, D. Assessment methods in human body composition. Curr Opin Clin Nutr Metab Care. 2008;11:566-572.

4. Hingorjo MR, Zehra S, Imran E, Qureshi MA. Neck circumference: a supplemental tool for the diagnosis of metabolic syndrome. J Pak Med Assoc. 2016:66:1221-1226.

5. Preis SR, Massaro JM, Hoffmann U, D'Agostino RB, Levy D, Robins SJ, et al. Neck circumference as a novel measure of cardiometabolic risk: the Framingham Heart study. J Clin Endocrinol Metab. 2010:95:3701-3710.

6. Garvey WT, Mechanick JI, BrettEM, Garber AJ, Hurley DL, Jastreboff AM, et al. American Association of Clinical Endocrinologists and American College of Endocrinology comprehensive clinical practice guidelines for medical care of patients with obesity. Executive summary. Endocr Pract. 2016:22:842-884.

7. Klein S, Allison DB, Heymsfield SB, Kelley DE, Leibel RL, Nonas C, et al. Waist circumference and cardiometabolic risk: a consensus statement from Shaping America's Health: Association for Weight Management and Obesity Prevention; NAASO, the Obesity Society; the American Society for Nutrition; and the American Diabetes Association. Am J Clin Nutr. 2007;15:1061-1067.

8. Kroll C, Mastroeni SSBS, Czarnobay SA, Ekwaru JP, Veugelers PJ, Mastroeni MF. The accuracy of neck circumference for assessing overweight and obesity: a systematic review and meta-analysis. Ann Hum Biol. 2017;44:667-677.

9. Koppad AK, Kaulgud RS, Arun BS. A study of correlation of neck circumference with Framingham Risk Score as a predictor of coronary artery disease. J Clin Diagn Res. 2017;11:OC17-OC20.

10. Özkaya I, Tunckale A. Neck circumference positively related with centra obesity and overweight in Turkish university students: a preliminary study. Cent Eur J Public Health. 2016;24:91-94.

11. Onat A, Hergenç G, Yüksel H, Can G, Ayhan E, Kaya Z, et al. Neck circumference as a measure of central obesity: associations with metabolic syndrome and obstructive sleep apnea syndrome beyond waist circumference. Clin Nutr. 2009;28:46-51.

12. Tom C, Roy B, Vig R, Kang DW, Aysola RS, Woo MA, et al. Correlations between waist and neck circumferences and obstructive sleep apnea characteristics. Sleep Vigil. 2018;2:111-118

13. Martinho FL, Tangerina RP, Moura SM, Gregório LC, Tufik S, Bittencourt LR. Systematic head and neck physical examination as a predictor of obstructive sleep apnea in class III obese patients. Braz J Med Biol Res. 2008;41:1093-1097.

14. Da Silva CC, Zambon MP, Vasques AC, Rodrigues AM, Camilo DF, Antonio MÂ, et al. Neck circumference as a new anthropometric indicator for prediction of insulin resistance and components of metabolic syndrome in adolescents: Brazilian Metabolic Syndrome Study. Rev Paul Pediatr. 2014;32:221-229.

15. Ben-Noun, L., Laor, A. Relationship between changes in neck circumference and changes in blood pressure. Am J Hypertens. 2004;17:409-414.

16. Borel AL, Coumes S, Reche F, Ruckly S, Pépin JL, Tamisier R, et al. Waist, neck circumferences, waist-to-hip ratio: Which is the best cardiometabolic risk marker in women with severe obesity? The SOON cohort. PLoS One. 2018;13:e0206617.

17. Luo $Y$, Ma X, Shen $Y, X u Y$, Xiong $Q$, Zhang X, et al. Neck circumference as an effective measure for identifying cardiometabolic syndrome: a comparison with waist circumference. Endocrine. 2017;55:822-830.

18. Assyov $Y$, Gateva A, Tsakova A, Kamenov Z. A comparison of the clinical usefulness of neck circumference and waist circumference in individuals with severe obesity. Endocr Res. 2017;42:6-14.

19. Yang L, Samarasinghe YP, Kane P, Amiel SA, Aylwin SJ. Visceral adiposity is closely correlated with neck circumference and represents a significant indicator of insulin resistance in WHO grade III obesity. Clin Endocrinol (Oxf). 2010;73:197-200

20. Ali MK, Echouffo-Tcheugui J, Williamson DF. How effective were lifestyle interventions in real-world settings that were modeled on the Diabetes Prevention Program? Health Aff (Millwood). 2012;31:67-75.

21. Lohman TG, Roche AF, Martorell R (editores.). Anthropometric standardization reference manual. EEUU: Human Kinetics Books; 1988.

22. Norma Oficial Mexicana NOM-030-SSA2-2009, para la prevención, detección, diagnóstico, tratamiento y control de la hipertensión arterial sistémica. México: Diario Oficial de la Federación; 2010.

23. Alberti KG, Eckel RH, Grundy SM, Zimmet PZ Cleeman II, Donato KA, et al. Harmonizing the metabolic syndrome: a joint interim statement of the International Diabetes Federation Task Force on Epidemiology and Prevention; National Heart, Lung, and Blood Institute; American Heart Association; World Heart Federation; International Atherosclerosis Society; and International Association for the Study of Obesity. Circulation. 2009;120:1640-1645.

24. Obesity: preventing and managing the global epidemic. Report of a WHO Consultation (WHO Technical Report Series 894). Suiza: World Health Organization, 2000.

25. Neta G Johnson KE Informing real-world practice with real-world evidence: the value of PRECIS-2. BMC Med. 2018;16:76.

26. Joshipura K, Muñoz-Torres F, Vergara J, Palacios C, Pérez CM. Neckcircumference may be a better alternative to standard anthropometric measures. J Diabetes Res. 2016;2016:6058916. 